\title{
One, No One and One Hundred Thousand: Patterns of chronic prostatic inflammation and infection
}

\author{
KONSTANTINOS STAMATIOU ${ }^{1}$, EVANGELIA SAMARA ${ }^{1}$, RICHARD NICOLAS LACROIX ${ }^{2}$, \\ HIPPOCRATES MOSCHOURIS ${ }^{1}$, GIANPAOLO PERLETTI ${ }^{3,4}$ and VITTORIO MAGRI ${ }^{5}$
}

\author{
${ }^{1}$ Department of Urology, Tzaneion Hospital, 18536 Piraeus; ${ }^{2}$ Department of Public and Community Health, \\ University of West Attica, Egaleo, 12241 Athens, Greece; ${ }^{3}$ Department of Biotechnology and Life Sciences, \\ University of Insubria, I-21100 Varese, Italy; ${ }^{4}$ Faculty of Medicine and Medical Sciences, \\ Ghent University, 3K3 9000 Ghent, Belgium; ${ }^{5}$ Urology Secondary Care Clinic, ASST-Nord, I-20092 Milan, Italy
}

Received January 24, 2020; Accepted February 18, 2021

DOI: $10.3892 / \mathrm{etm} .2021 .10398$

\begin{abstract}
Chronic prostatic inflammation may be classified into three types that share similar symptoms and are distinguished on the basis of microbiological findings. In the present study, consecutive cases of chronic prostatic inflammation and infection were retrospectively reviewed in order to explore the clinical course and long-term outcomes. The cohort consisted of patients with symptoms of prostatitis who visited the Urology Clinic of the Tzaneion Hospital (Piraeus, Greece) between March 2009 and March 2019. The patients were subjected to the Meares and Stamey '4-glass' test and patients with febrile prostatitis were evaluated with a single mid-stream 'clean' urine sample culture. Bacterial identification was performed using the Vitek 2 Compact system and the sensitivity test with the disc and the Vitek 2 system. A total of 656 patients with prostatitis-like symptoms with 1,783 visits for investigation and follow-up were reviewed and patients were divided into two major groups. Group 1 consisted of 549 cases with a single set of chronic prostatitis (CP)-like symptoms assessed in up to three visits. National Institutes of Health (NIH) category II CP (NIH-II) was most frequently diagnosed in those patients (37,6\%). At the follow-up, 125 patients were identified as having a type of $\mathrm{CP}$ different from that determined initially. Group 2 (107 cases) had recurring episodes of prostatitis-like symptoms assessed or confirmed over the course of 4-18 visits. Most patients (54.2\%) were initially diagnosed with NIH-II followed by disease-free periods and recurrence/reinfection or by shifts to NHI-IIIB. In conclusion, CP remains a poorly understood $\mathrm{n}$ medical condition characterized by a variety of
\end{abstract}

Correspondence to: Dr Konstantinos Stamatiou, Department of Urology, Tzaneion Hospital, 1 Afenfouli Ave, 18536 Piraeus, Greece E-mail: stamatiouk@gmail.com

Key words: chronic prostatitis, chronic bacterial prostatitis, chronic prostatitis/chronic pelvic pain syndrome, prostate, infection, antibiotics, susceptibility, Meares-Stamey test clinical manifestations and by transitions between different $\mathrm{CP}$ classes during its course.

\section{Introduction}

In Luigi Pirandello's novel 'One, No One and One Hundred Thousand', the protagonist comes to the realization that everyone he knows and everyone he has ever met has constructed his persona in their own imagination and that none of these personas corresponds to the image that he believes himself to be. In a similar manner, patients, urologists, pathologists, family physicians and microbiologists have different perceptions on chronic prostatic inflammation. This condition features a variety of symptoms that may differ from patient to patient. The most common symptoms include pain or discomfort in the genital or the pelvic area, which may or may not be associated with urinary disorders and/or sexual dysfunction. Premature ejaculation, hemospermia and increased serum prostate-specific antigen levels may be also present (1). Patients with a previous episode of chronic prostatitis (CP) are more likely to experience future episodes (2). There are 3 types of chronic prostatic inflammation that share similar symptoms, namely National Institutes of Health (NIH) category II chronic bacterial prostatitis (CBP) and cat. III CP/chronic pelvic pain syndrome (CP/CPPS), in its inflammatory (IIIB) and non-inflammatory (IIIB) variants (1). These syndromes are characterized by a rather long-term remitting and relapsing clinical course (that can last from several months to decades) and are distinguished on the basis of microbiological findings.

During urology referral service, it was noticed that patients referred with the tentative diagnosis of prostatitis are misdiagnosed and actually have a different condition oftentimes. Several patients that were ultimately found to have a positive Meares and Stamey test had a prior negative test. A notable number of patients with a prior diagnosis of CBP and clinical recurrence were ultimately found to have a negative Meares and Stamey test while some patients are presenting with different type of prostatitis overtime. To the best of our knowledge, there is a lot of outdated information about prostatitis and most studies on chronic prostatitis are focusing on 
treatment options, while the majority of them have a relatively short follow-up period.

In the present study, consecutive cases of chronic prostatic inflammation and infection were retrospectively reviewed in order to explore the clinical course (how the disease behaves over time) and long-term outcome. It should be noticed that no similar study has been published in the literature up to date.

\section{Materials and methods}

Patients. In the present retrospective study, the records of individual patient visits were analysed. Microbiological data [Meares and Stamey (MS) or two-glass tests and urethral smear cultures] and history (including general patient demographics, medical and surgical history and medication use) obtained from individuals with CP symptoms visiting the Urology Department of the Tzaneion Hospital (Piraeus, Greece) between March 2009 and March 2019 were retrospectively evaluated. Patients suffering from conditions that influence bacterial virulence or host response (e.g. immunodeficiency, abnormalities of the urogenital system) and patients who received antibiotics or immunosuppressive treatments within 4 weeks of the visit were excluded from the study (clinicopathological and demographic characteristics of included patients are presented in Table I).

Patient assessment. The patients included were clinically evaluated (interview, physical examination, National Institutes of Health Chronic Prostatitis Symptom Index (NIH-CPSI) and International Prostate Symptom Score (IPSS) questionnaires, ultrasound) and underwent the MS '4-glass' test, based on cultures of first-void (VB1), midstream/pre-prostatic massage (VB2), expressed prostatic secretions (EPS) and post-prostatic massage urine (VB3) specimens. Several patients underwent the simplified two-glass test, assessing the sole VB2 and VB3 specimens (1).

Microbiological evaluation. Identification and semi-quantitative assay for Mycoplasma hominis and Ureaplasma urealyticum were performed using the Mycoplasma IST-2 kit, according to the manufacturer's instructions (BioMerieux SA). Chlamydia trachomatis was detected by direct immunofluorescence (monoclonal antibodies against lipopolysaccharide membrane -ab54377-Kallestad Laboratories). Urine samples were cultured undiluted on blood and MacConkey agar plates (Kallestad Laboratories) and subjected to centrifugation for microscopic examination of the sediment (2). Evaluation of microbiological culture results was performed by two specialists. Microbiologists performed the evaluation independently and then compared the results. Any discrepancies were resolved through a consensus discussion.

Identification of traditional pathogens was performed by conventional methods and the Vitek-2 Compact (BioMerieux SA) system and susceptibility testing was performed by disc diffusion and/or the Vitek-2 system (BioMerieux SA). Interpretation of susceptibility results was based on Clinical and Laboratory Standards Institute guidelines and European Committee on Antimicrobial Susceptibility Testing guidelines (3).
Diagnosis. Differential diagnosis included any situation that causes symptoms similar to those of CP. Diagnosis of CP was based on the MS test or the two-glass test. For NIH-II, the test was considered positive if one of the following criteria was fulfilled: i) Bacteria grew in the culture of EPS and VB3 urine sample and did not in VB1 and VB2 sample; ii) bacterial colonies in VB3 were higher in number compared to VB1 and VB2 samples. Given that no standard cut-off level of the number of bacteria in both urine and prostate secretion samples is defined by consensus for the diagnosis of CBP, no lower acceptable level was defined for either one. Differentiation between NIH-IIIA and IIIB (inflammatory and non-inflammatory chronic nonbacterial prostatitis) was based on the presence of leukocytes in the EPS and/or the post-massage urine sample (2).

EPS/VB3 cultures that were considered negative (bacteria unable to grow) despite the presence of bacteria in the EPS/VB3 specimens were rated as cases with a 'likelihood of NIH-II'. Cases with a higher number of bacterial colonies in VB1 and VB2 compared to VB3 samples in the presence of positive EPS were considered as mixed chronic prostatitis/chronic cystitis cases (inflammation of the prostate and bladder that continues for 2 months or longer).

Appropriate antimicrobials were administered to confirmed cases of NIH-II according to the antibiogram for a period of 4 weeks. Patients who were diagnosed with non-bacterial prostatitis were offered multimodal therapy based on the main symptom (UPOINT phenotype: e.g. urinary: $\alpha$-blocker or antimuscarinic agent; organ-specific: Serenoa repens preparations; tenderness: Physical therapy) (4).

Evaluation of therapy outcomes. Upon clinical relapse or after four weeks of therapy, the NIH-CPSI and IPSS questionnaires were re-administered. Evaluation also included interview, physical examination, ultrasound and the '4-glass' or '2-glass' tests.

Statistical analysis. In order to analyze the persistence and recurrence of $\mathrm{CP}$, cases were stratified into two groups. Group 1 consisted of patients with a single set of CP-like symptoms and were recorded in up to three visits (including follow-up). Group 2 was made up of cases with recurring episodes of prostatitis-like symptoms registered in $>3$ visits (owing to initial evaluation, symptom persistence and symptom recurrence investigation, as well as regular follow-up). Statistical analysis was performed with the SPSS version 11.0 statistical software package (SPSS, Inc.). The paired t-test was used to analyse differences between means. An alpha error inferior to 5\% $(\mathrm{P}<0.05)$ was set as significance level for each comparison.

\section{Results}

Overview. Out of the 2,002 total visits between March 2009 and March 2019, 218 visits were incompletely recorded and were excluded from the study. Finally, 1,783 visits for investigation of prostatitis-like symptoms and routine follow-up were reviewed.

A wide variety of major symptoms, subsidiary symptoms and symptom combinations was reported by the patients. Major symptoms were reported to begin slowly and have alternating periods of absence with moments of worsening. In most cases, symptoms lasted $>3$ months prior to diagnosis. However, 
Table I. Data regarding demography, history, diagnoses and outcomes.

\begin{tabular}{lr}
\hline Demography & Value \\
\hline Mean age (years), SD & $45.5( \pm 11.9)$ \\
Difference in mean age among chronic prostatitis subgroups & $\mathrm{P}=0.449$ \\
Difference in mean age among cured and uncured patients & $\mathrm{P}=0.624$ \\
History & $348 / 656(53)$ \\
Previous diagnosis of prostatitis (\%) & $132 / 656(20.1)$ \\
Previous diagnosis of epididymitis $(\%)$ & \\
Initial diagnosis (Group A and B), $(\%)$ & $96 / 656(16)$ \\
NIH-IIIB & $26 / 656(4.3)$ \\
NIH-IIIA & $35 / 656(5.8)$ \\
Cystitis/Prostatitis & $370 / 656(61.6)$ \\
NIH-II (CBP) & $6 / 656(1.0)$ \\
Cystitis & $68 / 656(11.3)$ \\
Likelihood of NIH-II & \\
Outcome (Group A and B) $(\%)$ & $76 / 656(12.6)$ \\
No cure & $422 / 656(70.2)$ \\
Cure & $103 / 656(17.1)$ \\
Unknown &
\end{tabular}

NIH, National Institutes of Health; SD, standard deviation.

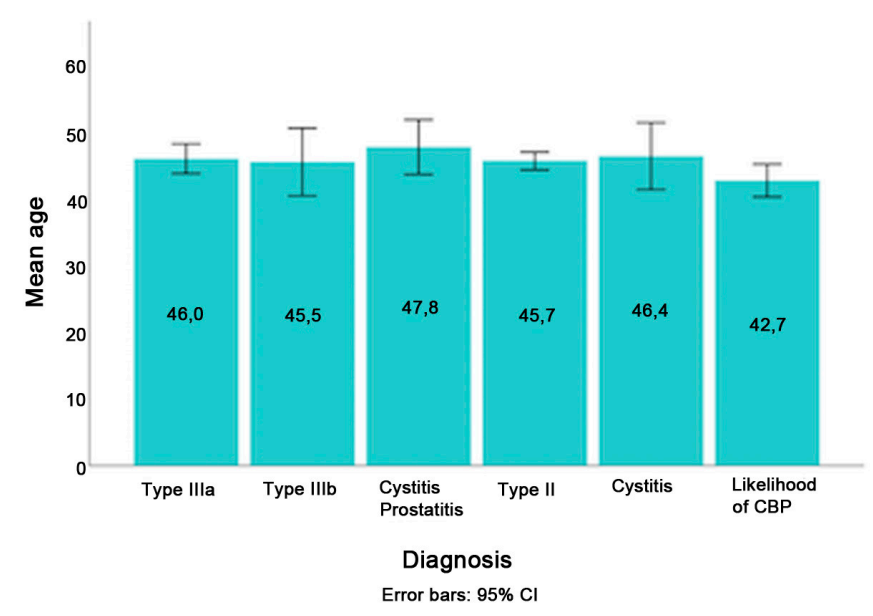

Figure 1. Associations between age variation and prostatitis subtypes. None of the prostatitis subtypes are significantly associated with a specific age group. CBP, chronic bacterial prostatitis

during relapse phases, the patients were able to promptly recognise the symptoms. The most frequent symptom was scrotal/testicular pain, accounting for almost $40 \%$ of the cases.

In total, 656 eligible patients were selected according to the inclusion/exclusion criteria. More than half of them (53\%) had a previous history of prostatitis. The mean age of these patients was $45.5 \pm 11.9$ years. Overall diagnoses and outcomes are presented in Table I. No statistically significant difference in mean age was identified among patients with different chronic prostatitis subtypes diagnosis $[\mathrm{F}(5)=0.948 ; \mathrm{P}=0.449]$ (Fig. 1). The mean age between cured (45.6 \pm 12.1 years) and uncured patients $(46.4 \pm 11.9$ years $)$ was also not significantly different $(\mathrm{P}=0.624$; Fig.2).

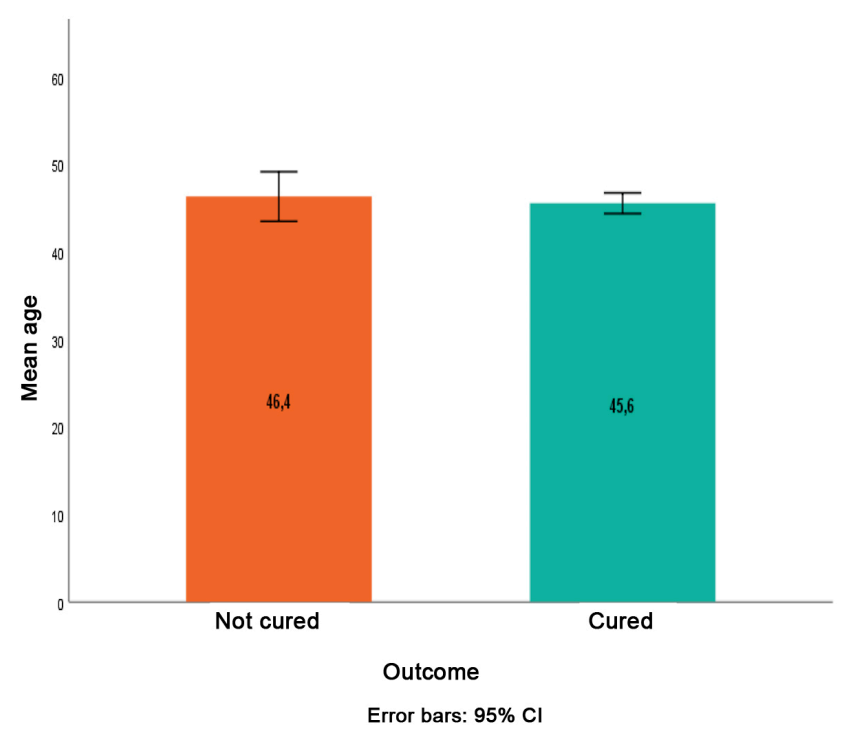

Figure 2. Associations between patients age and outcome. Patient age does not significantly influence the outcome.

Group 1. Group 1 consisted of 549 cases. A considerable fraction of patients $(44.9 \%$; 247/549) were diagnosed with NIH-II. A vast variety of bacteria were present in positive cultures, with Escherichia coli being the most common pathogen. However, coagulase-negative staphylococci (CoNS) (mainly S. hominis and S. haemolyticus) and Enterococcus faecalis were also common isolates. The second most frequent chronic prostatitis subtype was that of NIH-IIIB (12.39\%; 68/149). In 102 cases, some of (additional) symptoms did not fit the diagnosis and were attributed to diseases other than prostatitis. 
Table II. Presentation of patients with chronic prostatitis syndromes at the time of initial diagnosis and number of subsequent conditions assessed at the follow-up in the same patients. Group 1, first referral patients presenting with CP-like symptoms assessed in up to three visits. Conditions assessed at follow-up may exceed the number of initial cases, as patients may be diagnosed with the same condition multiple times during follow-up.

\begin{tabular}{|c|c|c|c|c|c|c|c|c|c|c|}
\hline \multirow[b]{2}{*}{$\begin{array}{l}\text { Initial } \\
\text { diagnosis }\end{array}$} & \multirow{2}{*}{$\begin{array}{c}\text { Total } \\
\text { patients } \\
\text { initially } \\
\text { diagnosed }\end{array}$} & \multicolumn{9}{|c|}{ Newly diagnosed conditions, cured cases or temporary disease-free cases assessed during follow-up } \\
\hline & & $\begin{array}{c}\mathrm{CBP} \\
\text { reinfection/ } \\
\text { recurrence }\end{array}$ & $\begin{array}{c}\text { Likelihood } \\
\text { of CBP }\end{array}$ & $\begin{array}{l}\text { Cystitis } \\
\text { and CBP }\end{array}$ & $\begin{array}{c}\mathrm{CP} / \\
\text { CPPS IIIA }\end{array}$ & $\begin{array}{c}\text { CP/ } \\
\text { CPPS IIIB }\end{array}$ & $\begin{array}{c}\text { Other } \\
\text { diagnosis }\end{array}$ & $\begin{array}{l}\text { Unknown } \\
\text { outcome }\end{array}$ & $\begin{array}{l}\text { Not } \\
\text { cured }\end{array}$ & Cured \\
\hline CBP & 247 & $\begin{array}{c}\text { See } \\
\text { 'not cured' }\end{array}$ & 7 & 5 & 14 & 46 & 3 & 20 & 14 & 139 \\
\hline $\begin{array}{l}\text { Likelihood } \\
\text { of CBP }\end{array}$ & 63 & 22 & $\begin{array}{c}\text { See } \\
\text { 'not cured' }\end{array}$ & 1 & 10 & 2 & 2 & 7 & 4 & 14 \\
\hline Cystitis and CBP & 31 & 0 & 2 & $\begin{array}{c}\text { See } \\
\text { 'not cured' }\end{array}$ & 2 & 2 & 0 & 6 & 0 & 19 \\
\hline CP/CPPS IIIA & 38 & 5 & 0 & 0 & $\begin{array}{c}\text { See } \\
\text { 'not cured' }\end{array}$ & 4 & 0 & 7 & 7 & 15 \\
\hline CP/CPPS IIIB & 68 & 9 & 4 & 0 & 2 & $\begin{array}{c}\text { See } \\
\text { 'not cured' }\end{array}$ & 7 & 10 & 16 & 20 \\
\hline Other diagnosis & 102 & 0 & 1 & 0 & 1 & 0 & $\begin{array}{c}\text { See } \\
\text { 'not cured' }\end{array}$ & 44 & 0 & 16 \\
\hline Total & 549 & 36 & 14 & 6 & 29 & 54 & 12 & 94 & 41 & 223 \\
\hline
\end{tabular}

CBP, chronic bacterial prostatitis; $\mathrm{CP}$, chronic prostatitis; CPPS, chronic pelvic pain syndrome.

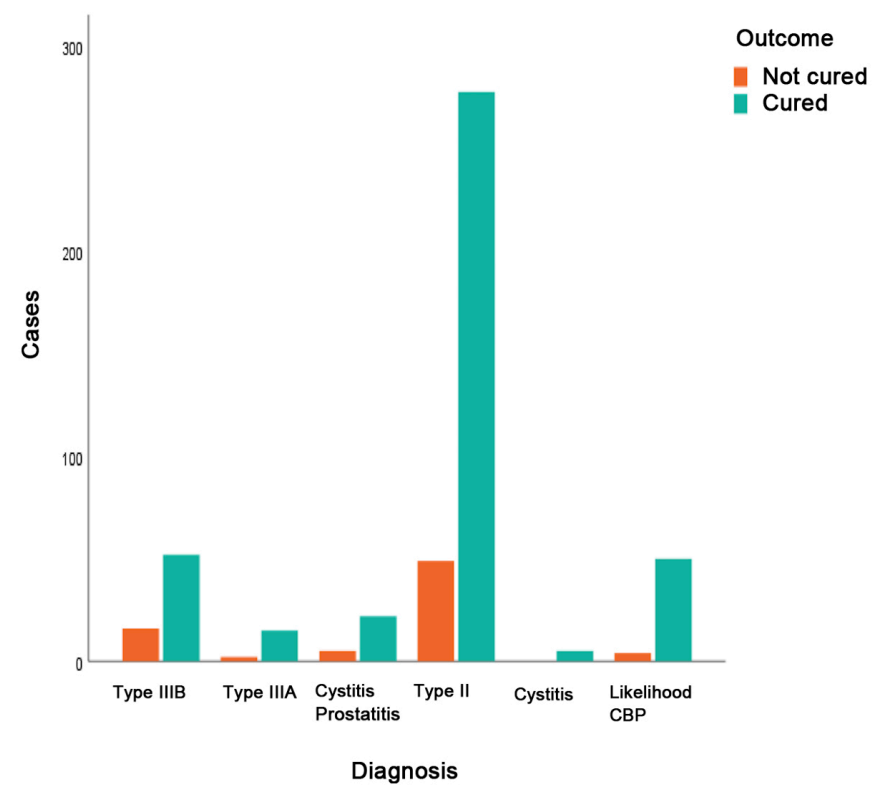

Figure 3. Associations between outcome and prostatitis subtype. The likelihood of a cure is significant only for a CBP diagnosis. CBP, chronic bacterial prostatitis

As far as the outcomes determined at the follow-up visits are concerned, clinical improvement accompanied by bacterial eradication was reported in 223 patients. A total of 41 patients reported clinical improvement despite bacterial persistence. In 14 cases, EPS/VB3 cultures were negative (bacteria unable to grow in culture) despite the presence of bacteria in the sample. Due to the absence of symptoms, these

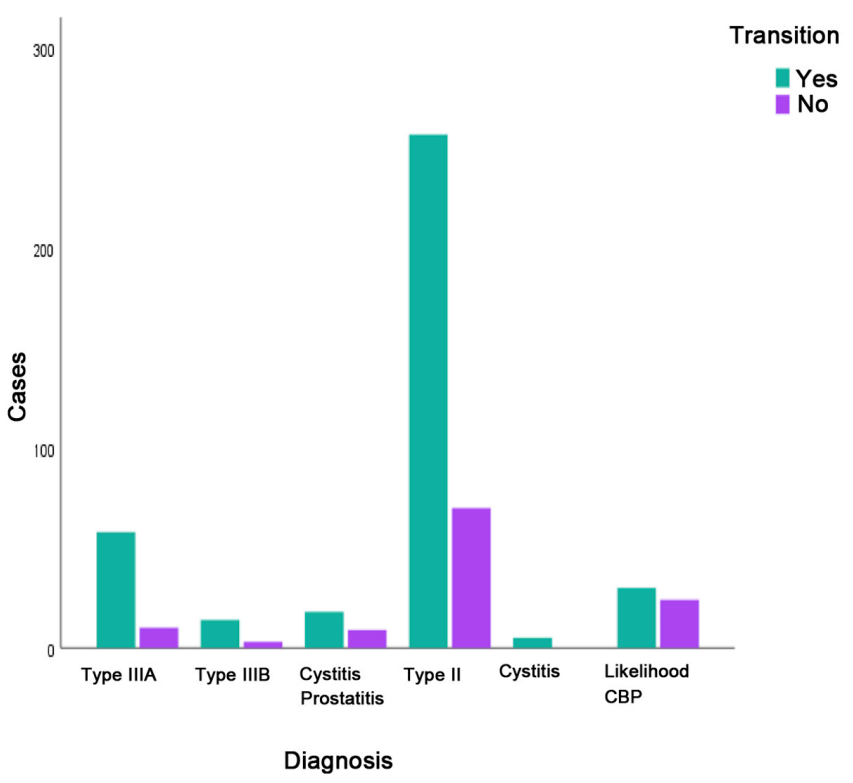

Figure 4. Prostatitis subtype and likelihood of transition. The likelihood of transition is more typical for CBP cases. CBP, chronic bacterial prostatitis

patients were not further evaluated. The clinical outcomes of 94 patients remained unknown, whereas 12 patients were diagnosed with diseases other than prostatitis. A total of six, 36, 29 and 54 patients who were initially diagnosed with mixed cystitis/prostatitis, NIH-II, NIH-IIIA and NIH-IIIB received the appropriate treatments and were fully re-evaluated at the 3rd visit. Initial diagnosis and outcomes determined at the follow-ups are presented in Table II. 
Table III. Presentation of patients with chronic prostatitis syndromes at the time of initial diagnosis and number of subsequent conditions occurring thereafter in the same group of patients. Group 2, patients with recurring episodes of CP-like symptoms assessed in $>3$ (and up to18) consecutive visits. Conditions assessed at follow-up may exceed the number of initial cases, as patients may be diagnosed with the same condition multiple times during follow-up.

\begin{tabular}{|c|c|c|c|c|c|c|c|c|c|}
\hline \multirow[b]{2}{*}{$\begin{array}{l}\text { Initial } \\
\text { diagnosis }\end{array}$} & \multirow{2}{*}{$\begin{array}{c}\text { Total } \\
\text { patients } \\
\text { initially } \\
\text { diagnosed }\end{array}$} & \multicolumn{8}{|c|}{ Newly diagnosed conditions, cured cases or temporary disease-free cases assessed during follow-up } \\
\hline & & $\begin{array}{l}\mathrm{CBP} \\
\text { reinfection/ } \\
\text { recurrence }\end{array}$ & $\begin{array}{c}\text { Likelihood } \\
\text { of CBP }\end{array}$ & $\begin{array}{l}\text { Cystitis } \\
\text { and CBP }\end{array}$ & $\begin{array}{c}\text { CP/ } \\
\text { CPPS IIIA }\end{array}$ & $\begin{array}{c}\text { CP/ } \\
\text { CPPS IIIB }\end{array}$ & $\begin{array}{l}\text { Disease- } \\
\text { free period }\end{array}$ & $\begin{array}{l}\text { Unknown } \\
\text { outcome }\end{array}$ & Cured \\
\hline CBP & 58 & 76 & 5 & 7 & 17 & 35 & 47 & 21 & 33 \\
\hline Likelihood of CBP & 27 & 27 & 0 & 1 & 4 & 3 & 6 & 2 & 22 \\
\hline Cystitis and CBP & 3 & 4 & 1 & 1 & 0 & 1 & 2 & 0 & 0 \\
\hline CP/CPPS IIIA & 9 & 15 & 1 & 0 & 5 & 5 & 6 & 1 & 8 \\
\hline CP/CPPS IIIB & 10 & 12 & 2 & 0 & 2 & 7 & 2 & 3 & 6 \\
\hline Total & 107 & 134 & 9 & 9 & 28 & 51 & 63 & 27 & 69 \\
\hline
\end{tabular}

CBP, chronic bacterial prostatitis; $\mathrm{CP}$, chronic prostatitis; $\mathrm{CPPS}$, chronic pelvic pain syndrome.

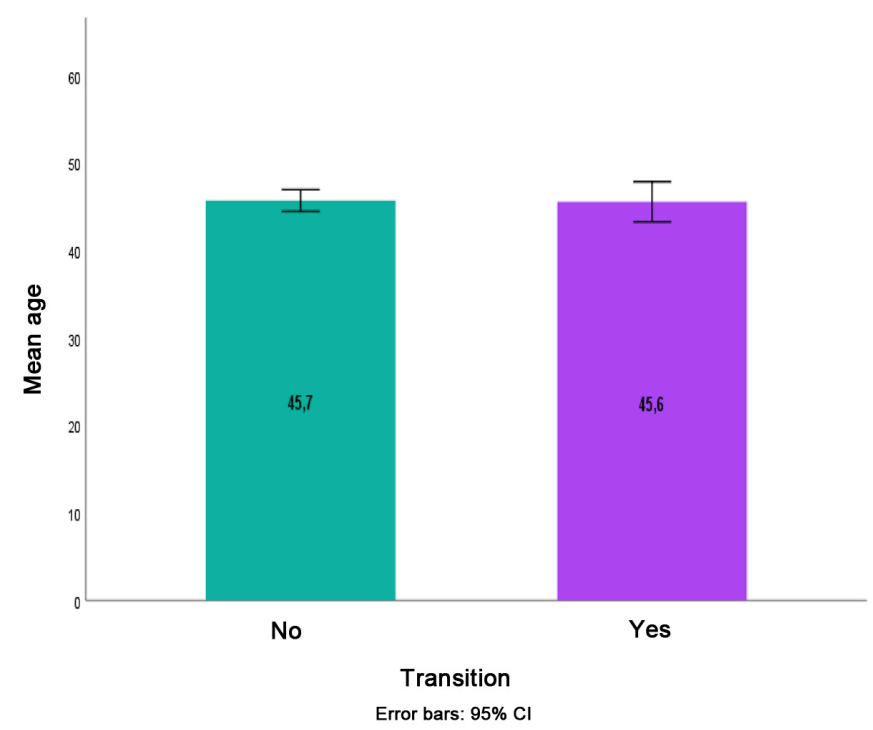

Figure 5. Age and likelihood of transition. Patient age does not significantly influence the likelihood of transition.

Group 2. Group 2 consisted of 107 cases. Most patients (54.2\%) were initially diagnosed with NIH-II, followed by recurrence or by disease-free periods and transition to NIH-IIIB. The average time interval between episodes of confirmed NIH-II was 13.9 months (range, 2-56 months). The pathogens most commonly associated with clinical relapses were Enterococcus faecalis, CoNS and E. coli. The second most frequent diagnosis was that of 'likelihood of NIH-II', characterized by negative EPS/VB3 cultures (i.e., bacteria present but unable to grow in culture) despite the presence of bacteria in the sample. Most of these cases were re-diagnosed as NIH-II reinfection/recurrence upon follow-up. Similarly, most NIH-IIIB and NIH-IIIA cases were re-diagnosed as NIH-II reinfection/recurrence. The time interval between initial diagnosis and recurrence ranged between 1 and 23 months (Table III). The association between initial diagnosis and final outcome was not statistically significant $(\mathrm{P}=0.214)$.
Table IV. Likelihood of transition secondary to initial diagnosis.

\begin{tabular}{lcccc}
\hline $\begin{array}{l}\text { Initial } \\
\text { diagnosis }\end{array}$ & $\begin{array}{l}\text { Type } \\
\text { IIIB }\end{array}$ & $\begin{array}{c}\text { Type } \\
\text { IIIA }\end{array}$ & $\begin{array}{c}\text { Cystitis } \\
\text { prostatitis }\end{array}$ & $\begin{array}{c}\text { Type II } \\
\text { (CBP) }\end{array}$ \\
\hline Type IIIB & $0(0,0)$ & $4(40,0)$ & $0(0,0)$ & $6(60,0)$ \\
Type IIIA & $2(66,7)$ & $0(0,0)$ & $0(0,0)$ & $1(33,3)$ \\
Cystitis-prostatitis & $4(44,4)$ & $5(55,6)$ & $0(0,0)$ & $0(0,0)$ \\
Type II (CBP) & $53(75,7)$ & $16(22,9)$ & $1(1,4)$ & $0(0,0)$ \\
Likelihood of CBP & $2(8,3)$ & $8(33,3)$ & $0(0,0)$ & $14(58,3)$ \\
\hline
\end{tabular}

Values are expressed as n (\%). CBP, chronic bacterial prostatitis.

However, the likelihood of cure was significant only for a CBP diagnosis ( $\mathrm{P}=0.001$; Fig.3).

The association between initial diagnosis and transition was statistically significant $\left[\chi^{2}(5)=20.324, P=0.001\right.$; Fig.4, Table IV]. Age was not associated with transition from a $\mathrm{CP}$ subtype to another CP subtype ( $\mathrm{P}=0.916)$ (Fig.5).

\section{Discussion}

At present, the MS test is considered the gold standard for the diagnosis of CP syndromes. However, strict definitions used to classify $\mathrm{CP}$ syndromes, together with certain drawbacks of the MS test (e.g. prostatic secretion cannot be obtained from all patients, clinical relapses are not always associated with positive EPS culture) frequently make it difficult to establish the diagnosis of CP or differentiate between the different CP syndromes. In the present study, only $29.1 \%$ of the MS tests provided sufficient amounts of EPS; thus, in the remaining cases $(70.9 \%)$, the diagnosis was only based on VB3 cultures. Traditionally, NIH-II is diagnosed by a 10 -fold increase in bacteria in the EPS or VB3 specimens compared with VB1 and VB2 (2). However, in a significant number of CBP cases in the present study (34\%), the increase in bacterial loads in VB3 specimens was between 2- and 
3-fold compared to VB1 and VB2. In a similar number of cases (32\%), leucocyte counts in VB3 specimens were slightly higher than those in VB1 and/or VB2. Actually, white blood cell (leucocyte) counts have not been indicated to correlate with symptoms or with the presence or absence of infection (4). On the one hand, high counts of leucocytes and positive bacterial cultures may be present in asymptomatic patients (5); on the other hand, leucocytes may be absent in symptomatic patients with Gram-positive bacterial cultures $(6,7)$. Furthermore, in the present study, a significant number of false-negative cases (classified as 'likelihood of NIH-II') was recorded in both groups (63/549 and 27/107 in groups 1 and 2, respectively). Of note, certain patients may have bacterial infection despite the fact that such pathogens are unable to grow in cultures of urine specimens. Certain experts debate the role of Gram-positive organisms other than Enterococci $(8,9)$ and it has been suggested that urologic diseases involving Gram-positive bacteria may be easily overlooked due to the limitations of culture-based assays typically utilized for urine in hospital microbiology laboratories (10). Negative culture results may also occur for various other reasons, including for example the presence of fastidious organisms, the initiation of empirical antibiotic therapy prior to obtaining an EPS sample, high bacterial count cut-offs established by laboratories (e.g. a threshold of 50,000 colony-forming units to report a test culture as 'positive') or insufficient sample volumes. Technical difficulties in performing prostatic massage (e.g. under the circumstances of obesity, rectal discomfort or recent ejaculation) actually increase the risk of under-sampling prostatic secretions (11).

According to the Stamey Meyers protocol patients should avoid ejaculation for 4 days prior to the test. However, this was not possible for numerous patients. Therefore, recent ejaculation is the likely reason explaining the low number of assessable EPS samples in the present study. On the other hand, the presence of fastidious organisms, anaerobic pathogens or bacteria not detectable with the usual tests may explain cases characterized by negative EPS/VB3 cultures despite the actual presence of bacteria and no recent exposure to antibiotic intake reported. In the present study, the bacteriologically proven incidence of NIH-II among males with prostatitis symptoms was high. A possible explanation is possibly the fact that no lower acceptable level for bacterial colonies in both urine and prostate secretion samples for the diagnosis of CBP was defined in the present study. In addition, the fact that certain Gram-positive bacteria were recognised as pathogenic may have also contributed to this difference. Similar to what was reported in the present study, other studies indicated a high NIH-II incidence and prevalence of Gram-positive bacterial strains (12-14). The incidence of NIH-II was even greater, given that obligate intracellular parasites and intracellular bacterial communities in the human urinary tract are not detectable by simple urinalysis (15). A large prospective study of males with CP indicated that $74 \%$ had an infectious etiology. However, in that study, the most common isolate was Chlamydia trachomatis (37\% of cases) (16).

All of these considerations imply a new understanding of $\mathrm{CP}$ and raise questions about the clinical usefulness of the standard MS test as a diagnostic tool in males with suspected $\mathrm{CP}$. Yet, regardless of its drawbacks, the four-glass test is useful for identifying infections with certain pathogens. However, this test should be improved in order to increase its relative sensitivity and specificity for both traditional and unusual pathogens. Furthermore, as the distinction between NIH type IIIA and NIH type IIIB may be biased by a non-optimal preparation of patients (incorrect cleaning of genital area, recent ejaculation, hyperhydration and the consequent low specific gravity of the urine), the need for guidelines on the preparation of patients prior to the SM test is imperative.

Paradoxically, CP may also be considered as a single 'disease'. As indicated in the present study, type IIIA and type IIIB may represent the evolution of this disease following an initial diagnosis of NIH-II, thus representing a condition characterized by the persistence of CP symptoms despite bacterial eradication. They may also precede or follow NIH-II relapses and/or disease-free periods. In such a case, a transition of CBP to NIH type IIIB and NIH type IIIA and vice versa is not to be excluded.

$\mathrm{CP}$ remains a poorly understood medical condition characterized by a variety of clinical manifestations and by transitions between different $\mathrm{CP}$ classes during its course The diagnosis is hard due to the absence of typical clinical symptoms and the distinction between CP syndromes (bacterial/non-bacterial and inflammatory/non-inflammatory types) is based on the presence or absence of bacteria and/or inflammatory cells in the EPS and VB3 specimens. However, a variety of situations may shift the diagnosis to one or another direction. While the topic of CP remains somewhat obscure, strict criteria for differentiating types of prostatitis frequently render the interpretation of the culture results difficult. As new evidence is added to this understudied field of research, the current perception of CP may be challenged.

\section{Acknowledgements}

The authors wish to thank Dr Kurt G Naber, Assoc. Professor of Urology at the Technical University of Munich School of Medicine for his critical suggestions.

\section{Funding}

No funding was received.

\section{Availability of data and materials}

The datasets used and/or analyzed during the current sudy are available from the corresponding author on reasonable request.

\section{Authors' contributions}

SK, ES and RNL conceived and designed the study. SK, HM and VM performed a literature search. SK, ES and HM acquired the data and confirm the authenticity of the raw data. SK, ES, RNL and GP analyzed and interpreted the data. RNL, VM and GP performed critical analysis and review of the literature. SK, ES and GP drafted the manuscript. RNL, HM and VM critically revised the article for important intellectual content. All authors read and approved the final manuscript.

\section{Ethics approval and consent to participate}

Not applicable. 


\section{Patient consent for publication}

Not applicable.

\section{Competing interests}

The authors declare that they have no competing interest.

\section{References}

1. Vaidyanathan R and Mishra VC: Chronic prostatitis: Current concepts. Indian J Urol 24: 22-27, 2008.

2. Stamatiou K, Magri V, Perletti G, Papadouli V, Recleiti N, Mamali V and Zarkotou O: Chronic prostatic infection: Microbiological findings in two Mediterranean populations. Arch Ital Urol Androl 91: 177-181, 2019.

3. Kassim A, Omuse G, Premji Z and Revathi G: Comparison of Clinical Laboratory Standards Institute and European Committee on Antimicrobial Susceptibility Testing guidelines for the interpretation of antibiotic susceptibility at a University teaching hospital in Nairobi, Kenya: A cross-sectional study. Ann Clin Microbiol Antimicrob 15: 21, 2016.

4. Magri V, Marras E, Restelli A, Wagenlehner FM and Perletti G: Multimodal therapy for category III chronic prostatitis/chronic pelvic pain syndrome in UPOINTS phenotyped patients. Exp Ther Med 9: 658-666, 2015.

5. Nickel JC, Alexander RB, Schaeffer AJ, Landis JR, Knauss JS and Propert KJ; Chronic Prostatitis Collaborative Research Network Study Group: Leukocytes and bacteria in men with chronic prostatitis/chronic pelvic pain syndrome compared to asymptomatic controls. J Urol 170: 818-822, 2003.

6. Kohnen PW and Drach GW: Patterns of inflammation in prostatic hyperplasia: A histologic and bacteriologic study. J Urol 121: 755-760, 1979

7. Potts J and Payne RE: Prostatitis: Infection, neuromuscular disorder, or pain syndrome? Proper patient classification is key. Cleve Clin J Med 74 (Suppl 3): S63-S71, 2007.
8. Krieger JN, Ross SO, Limaye AP and Riley DE: Inconsistent localization of gram-positive bacteria to prostate-specific specimens from patients with chronic prostatitis. Urology 66: 721-725, 2005

9. Naber KG: Management of bacterial prostatitis: What's new? BJU Int 101 (Suppl 3): 7-10, 2008.

10. Kline KA and Lewis AL: Gram-Positive Uropathogens, Polymicrobial Urinary Tract Infection, and the Emerging Microbiota of the Urinary Tract. Microbiol Spectr 4: 10, 2016.

11. Wagenlehner FM, Naber KG, Bschleipfer T, Brähler E and Weidner W: Prostatitis and male pelvic pain syndrome: Diagnosis and treatment. Dtsch Arztebl Int 106: 175-183, 2009.

12. Cai T, Mazzoli S, Meacci F, Boddi V, Mondaini N, Malossini G and Bartoletti R: Epidemiological features and resistance pattern in uropathogens isolated from chronic bacterial prostatitis. J Microbiol 49: 448-454, 2011.

13. Colodner R, Ken-Dror S, Kavenshtock B, Chazan B and Raz R: Epidemiology and clinical characteristics of patients with Staphylococcus saprophyticus bacteriuria in Israel. Infection 34: 278-281, 2006

14. Novo-Veleiro I, Hernández-Cabrera M, Cañas-Hernández F, Pisos-Álamo E, Francés-Urmeneta A, Delgado-Yagüe M, Alvela-Suárez L and Pérez-Arellano JL: Paucisymptomatic infectious prostatitis as a cause of fever without an apparent origin. A series of 19 patients. Eur J Clin Microbiol Infect Dis 32: 263-268, 2013

15. Rosen DA, Hooton TM, Stamm WE, Humphrey PA and Hultgren SJ: Detection of intracellular bacterial communities in human urinary tract infection. PLoS Med 4: e329, 2007.

16. Skerk V, Krhen I, Schonwald S, Cajic V, Markovinovic L, Roglic S, Zekan S, Andracevic AT and Kruzic V: The role of unusual pathogens in prostatitis syndrome. Int J Antimicrob Agents 24 (Suppl 1): S53-S56, 2004

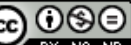

This work is licensed under a Creative Commons Attribution-NonCommercial-NoDerivatives 4.0 International (CC BY-NC-ND 4.0) License. 